UDC 67.404 .014

Submitted: 03.06.2020

LBC 34.096, 342.728

Accepted: 23.06.2020

\title{
THE CONCEPT, PRINCIPLES AND TYPES OF PUBLIC CONTROL OF PUBLIC PROCUREMENT IN RUSSIA:

\author{
THE LEGAL ANALYSIS
}

\author{
Roman Yu. Burimov \\ Astrakhan State University, Astrakhan, Russian Federation
}

Oleg A. Ibragimov

The Academy of Management of the Ministry of Internal Affairs of Russia, Moscow, Russian Federation

Introduction: the authors analyze some controversial scientific initiatives in relation to the concept and principles of public control, whose relevance is justified by the need to improve the implementation of the authorities' public interests. The paper also discusses the various types of social control, distributed according to the criteria. The purpose of the work is to develop proposals for the development of the legal regulation of public control in the field of public procurement. Methods: the main method of research is the dialectical method of cognition. The paper also uses the system-functional, historical and logical methods. Results: supplementing the theoretical research on public control with the scientific conclusions concerning its concept, principles, and types. Conclusions: according to the results of the study, it is proposed to supplement the term "public control" with the goals of monitoring and the principle of retribution of citizens' participation in the activities of public control of the individual authorities. The classifications of general and special types of control developed by the authors will allow expanding the existing theoretical and methodological base of the research object.

Key words: public control, public procurement, general and special types of control, surveillance, retribution.

Citation. Burimov R.Yu., Ibragimov O.A. The Concept, Principles and Types of Public Control of Public Procurement in Russia: The Legal Analysis. Legal Concept, 2020, vol. 19, no. 3, pp. 84-90. (in Russian). DOI: https://doi.org/10.15688/lc.jvolsu.2020.3.11

ББК 67.404 .014

УДК 34.096, 342.728

Дата поступления статьи: 03.06.2020

Дата принятия статьи: 23.06.2020

\section{ПОНЯТИЕ, ПРИНЦИПЫ И ВИДЫ ОБЩЕСТВЕННОГО КОНТРОЛЯ ГОСУДАРСТВЕННЫХ ЗАКУПОК В РОССИИ: ЮРИДИЧЕСКИЙ АНАЛИЗ}

\author{
Роман Юрьевич Буримов \\ Астраханский государственный университет, г. Астрахань, Российская Федерация
}

Олег Александрович Ибрагимов

Академия управления МВД России, г. Москва, Российская Федерация

Введение: авторами проводится анализ некоторых дискуссионных научных инициатив по отношению к понятию и принципам деятельности по общественному контролю, актуальность которых обосновывается необходимостью совершенствования реализации публичных интересов органов власти. Также в статье рассматриваются различные виды общественного контроля, распределенные по критериям. Целью исследования является разработка предложений, касающихся развития нормативно-правового регулирования деятель- 
ности по общественному контролю в сфере государственных закупок. Методы: основным методом исследования является диалектический метод познания. В статье также используются системно-функциональный, исторический и логический методы. Результаты: дополнение теоретических исследований по общественному контролю научными выводами, касающимися его понятия, принципов и видов. Выводы: по результатам исследования предложено дополнить термин «общественный контроль» целями наблюдения и принципом возмездности участия граждан в деятельности по общественному контролю отдельных органов власти. Разработанные авторами классификации общих и специальных видов контроля позволят расширить существующую теоретико-методологическую базу объекта исследования.

Ключевые слова: общественный контроль, государственные закупки, общие и специальные виды контроля, наблюдение, возмездность.

Цитирование. Буримов Р. Ю., Ибрагимов О. А. Понятие, принципы и виды общественного контроля государственных закупок в России: юридический анализ // Legal Concept $=$ Правовая парадигма. $-2020 .-$ T. 19, № 3. - C. 84-90. - DOI: https://doi.org/10.15688/lc.jvolsu.2020.3.11

\section{Введение}

Важнейшее направление формирования устойчивых основ народовластия в Российской Федерации - непосредственное участие граждан во власти. Одной и таких форм участия граждан является общественный контроль органов власти.

Во многих развитых странах Западной Европы и США применяется законодательство, позволяющее субъектам гражданского общества контролировать федеральный, региональный и местные бюджеты, с момента их создания до целевого использования [15, c. 77-78]. В России правом контроля государственных закупок наделены субъекты общественного контроля, которыми могут выступать как граждане, так и созданные ими общественные организации в рамках действующего законодательства.

Эффективная система общественного контроля государственных закупок предполагает совершенствование ее теоретико-методологической основы, разработанной с учетом успешно сложившей правоприменительной практики.

\section{Понятие}

Официальное определение общественного контроля закреплено в ст. 4 Федерального закона от 21 июля 2014 г. № 212-ФЗ «Об основах общественного контроля в Российской Федерации» [12] (далее- Закон об общественном контроле). Многие исследователи отмечают недостатки и противоречивость некоторых дефиниций, используемых в данном определении.
Наблюдение - целенаправленное восприятие, обусловленное задачей деятельности и трактуемое во многих отраслях научного знания как один из методов эмпирического исследования, состоящее в преднамеренном, систематическом и целенаправленном восприятии процессов и явлений $[2 ; 14]$. Следует согласиться с мнениями А.И. Авдеевой $[1$, с. 40$]$ и М.С. Крицкой $[7$, с. 21] о том, что понятие «наблюдение» не в полной мере отражает содержание контрольной деятельности. Само по себе понятие «наблюдение» является методом эмпирического исследования, результат которого определяется в зависимости от его целей. В данном случае цель общественного контроля - это наблюдение, которое само по себе определяет понятие контроля. Представляется, что определение «общественный контроль» целесообразно дополнить такой целью наблюдения, как проверка соответствия объектов общественного контроля выполнению возложенных на них функций и задач.

Авторские определения «общественного контроля» также предлагаются в других научных исследованиях. Анализ определений А.И. Авдеевой [1, с. 26], О.С. Забраловой [4, с. 18], С.М. Зубарева [5, с. 143], В.В. Старчиковой $[8$, с. 26$]$ показал, что общественный контроль они рассматривают как деятельность граждан или общественных объединений. Авторы не отождествляют контроль с функцией управления, что впоследствии позволило бы рассматривать общественный контроль в организации как один из процессов управленческой деятельности и внедрять его результаты в работу органа власти. С нашей 
точки зрения, общественный контроль следует рассматривать прежде всего в качестве составной части управления объектами и процессами, который возможно осуществлять непрерывно на всех этапах государственных закупок. У вышеназванных авторов различные позиции в определении целей общественного контроля: наблюдение и проверка деятельности органов власти, совершенствование управления, установление соответствия функционирования органов власти нормативноправовым стандартам, проверка соблюдения требований нормативных актов, устранение выявленных нарушений. Существенное различие целей общественного контроля связано с различными направлениями исследований авторов. В то же время указанные цели не противопоставляются, а скорее, дополняют друг друга.

С учетом предложенных дополнений определение «общественный контроль» предлагается изложить в следующей форме: «деятельность субъектов общественного контроля, осуществляемая посредством участия в процессе управления контролируемых объектов и заключающаяся в наблюдении за деятельностью органов государственной власти, органов местного самоуправления, государственных и муниципальных организаций, иных органов и организаций, осуществляющих в соответствии с федеральными законами отдельные публичные полномочия, целью которого является проверка соответствия объектов общественного контроля выполнению возложенных на них функций и задач, анализ и общественная оценка принимаемых ими решений и актов с учетом общественного мнения».

\section{Принципы}

Некоторые ученые (Е.В. Бердникова, О.А. Околеснова, В.В. Гончаров, М.А. Килессо и др.) считают, что перечень принципов, установленных Законом об общественном контроле, является неполным. Например, B.В. Гончаров отмечает необходимость включения в указанный перечень принципов этики и профессионализма представителей органов общественного контроля; коллегиальности в деятельности субъектов обществен- ного контроля; народовластия [3, с. 151]. По нашему мнению, принятие данных принципов не явилось бы важной поправкой в нормативный акт, так как их реализация не приведет к задуманным ученым правовым последствиям. Считаем, что значимыми являются дискуссии по поводу принципа безвозмездности общественного контроля. По мнению М.А. Килессо, список принципов стоит дополнить принципом «безвозмездность осуществления общественного контроля» [6, с. 30]. Автор данного предложения считает, что представители органов общественного контроля должны осуществлять свою деятельность безвозмездно. По сути это означает, что граждане, осуществляющие общественный контроль лично или в составе общественной организации, принимают участие в данной деятельности в свободное от работы время. На общественные организации распространяются все нормы трудового законодательства. Что касается тех субъектов общественного контроля, которые зарегистрированы как некоммерческие организации, труд их работников может быть как возмездным, так и безвозмездным (ч. 2 ст. 32 Федерального закона от 12.01.1996 № 7-Ф3 «О некоммерческих организациях» [10]). В ст. 13 Закона об Общественной палате [11] закреплены гарантии деятельности членов Общественной палаты Российской Федерации: освобождение работодателем от выполнения трудовых обязанностей по основному месту работы с сохранением за ним места работы (должности); выплата компенсаций и возмещение расходов, связанных с осуществлением полномочий члена Общественной палаты. Так, с одной стороны, принцип безвозмездности общественного контроля усиливает роль принципов самостоятельности и независимости субъектов общественного контроля, а с другой стороны - безвозмездное участие граждан в деятельности организации, осуществляющей общественный контроль и являющейся местом, где они выполняют трудовые обязанности, противоречит принципу права каждого работника на своевременную и в полном размере выплату справедливой заработной платы согласно ст. 2 Трудового кодекса Российской Федерации [9]. Законодателем гарантии возмещения неполученных трудовых доходов и 
Р.Ю. Буримов, О.А. Ибрагимов. Понятие, принципы и виды общественного контроля

трансакционных расходов в рамках общественного контроля установлены только для членов Общественной палаты, для других видов деятельности - законодательно не определены. В отношении такой сферы общественного контроля, как государственные закупки, зачастую требуется применение специальных знаний и навыков, необходимых для объективной оценки эффективности закупки в рамках экспертизы товара, работы или услуги. Привлечение компетентных экспертов предполагает наличие не только финансовых расходов, но и трансакционных издержек: ведение переговоров, заключение договоров, взаимодействие с заказчиком по экспертной работе и др. Следовательно, для отдельных сфер общественного контроля, таких как государственные закупки, актуальным является вопрос о предоставлении финансовых гарантий участникам общественного контроля.

\section{Виды}

С учетом многообразия видов общественного контроля предлагается рассматривать его общие и специальные виды.
Общие виды общественного контроля разработаны по критериям контрольной деятельности в отношении органов власти любого демократического государства, вне зависимости от форм правления и государственного устройства (рис. 1).

Некоторые общие виды общественного контроля предложенной классификации требуют пояснения. По контролируемому признаку выделяется качественный, количественный и альтернативный контроль по показателям деятельности органа власти. Например, качественным общественным контролем государственных закупок является соответствие фактического качества товара (работы, услуги) условиям государственного контракта. Аналогичное разъяснение по количественному признаку. Альтернативным контролем является, к примеру, проверка необходимости функционального значения товара (работы, услуги) потребности органа власти. По способу воздействия общественный контроль подразделяется на прямой и косвенный. Прямой общественный контроль предполагает прямое воздействие на орган власти: непосредственное взаимодействие с должностными лицами. Косвенный контроль

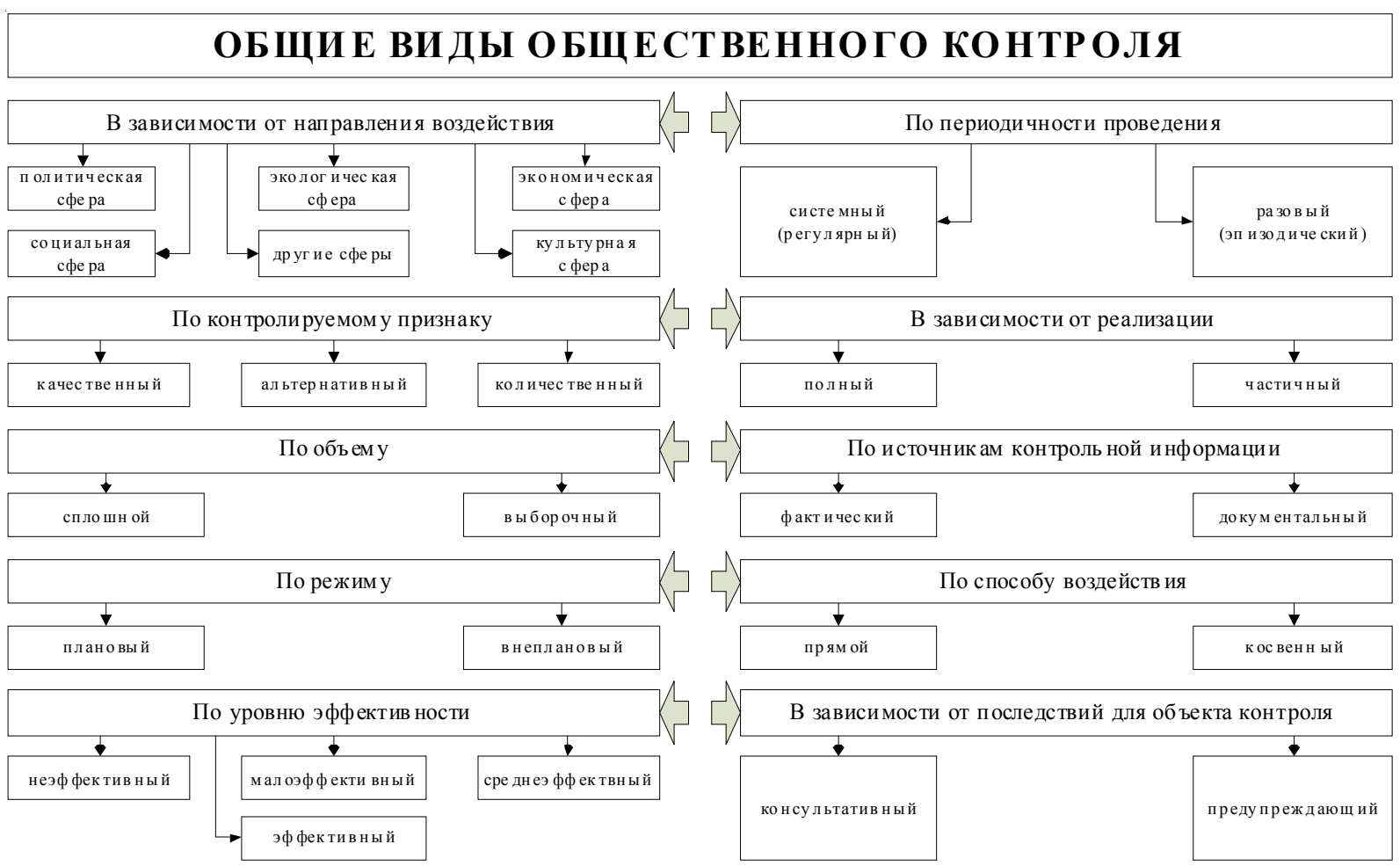

Рис. 1. Общие виды общественного контроля 
призван оказывать косвенное воздействие на орган власти: взаимодействие с должностными лицами вышестоящего органа посредством обращений в государственные органы контроля и надзора, публикация результатов контроля в средствах массовой информации и т. п. В зависимости от последствий для объекта выделяется консультативный и предупреждающий контроль. Предупреждающий контроль направлен на выявление ошибок и недостатков, а консультативный - на поиск более эффективных путей деятельности органа власти.

Специальные виды общественного контроля составлены с учетом общественных отношений, сложившихся в современной России, на основании правовых положений Закона об общественном контроле и Федерального закона от 5 апреля 2013 г. № 44-Ф3 «О контрактной системе в сфере закупок товаров, работ, услуг для обеспечения государственных и муниципальных нужд» [13] (рис. 2).

\section{Выводы}

В целях совершенствования теоретической и нормативно-правовой базы предлагается деятельность по общественному контролю включить в процессы управления объектами контроля и дополнить определение целями наблюдения. Для таких сфер общественного контроля, как государственные закупки, целесообразно применять принцип возмездности участия в контрольной деятельности. Раз- работанная авторами классификация общих видов общественного контроля универсальна для всех сфер, субъектов и объектов контроля. Классификация специальных видов общественного контроля применима к сфере государственных закупок в России.

\section{СПИСОК ЛИТЕРАТУРЫ}

1. Авдеева, А. И. Правовое регулирование общественного контроля за деятельностью органов государственной власти субъектов Российской Федерации : дис. ... канд. юрид. наук : 12.00.02 / Авдеева Арина Игоревна. - М., 2017. - 241 с.

2. Большой энциклопедический словарь. Электрон. текстовые дан. - Режим доступа : http:// znachenieslova.ru/slovar/encyclopedic/nablyudenie. Загл. с экрана.

3. Гончаров, В. В. Конституционно-правовые основы общественного контроля в Российской Федерации : монография / В. В. Гончаров. - М. : Alicegroup, 2019. - $256 \mathrm{c}$.

4. Забралова, О. С. Общественный контроль в Российской Федерации : монография / О. С. Забралова. - М. : Навигатор, 2011. - 122 с.

5. Зубарев, С. М. О федеральном законе «Об основах общественного контроля» / С. М. Зубарев // Проблемы науки административного права : материалы конф. «Лазаревские чтения» (20-21 ноября 2014 г.). - М. : Контакт, 2015. - С. 143-150.

6. Килессо, М. А. Принципы общественного контроля над деятельностью органов местного самоуправления в России / М. А. Килессо // Пробелы в российском законодательстве. - 2016. - № 2. C. 24-30.

\section{СПЕЦИАЛЬНЫЕ ВИДЫ ОБЩЕСТВЕННОГО КОНТРОЛЯ}

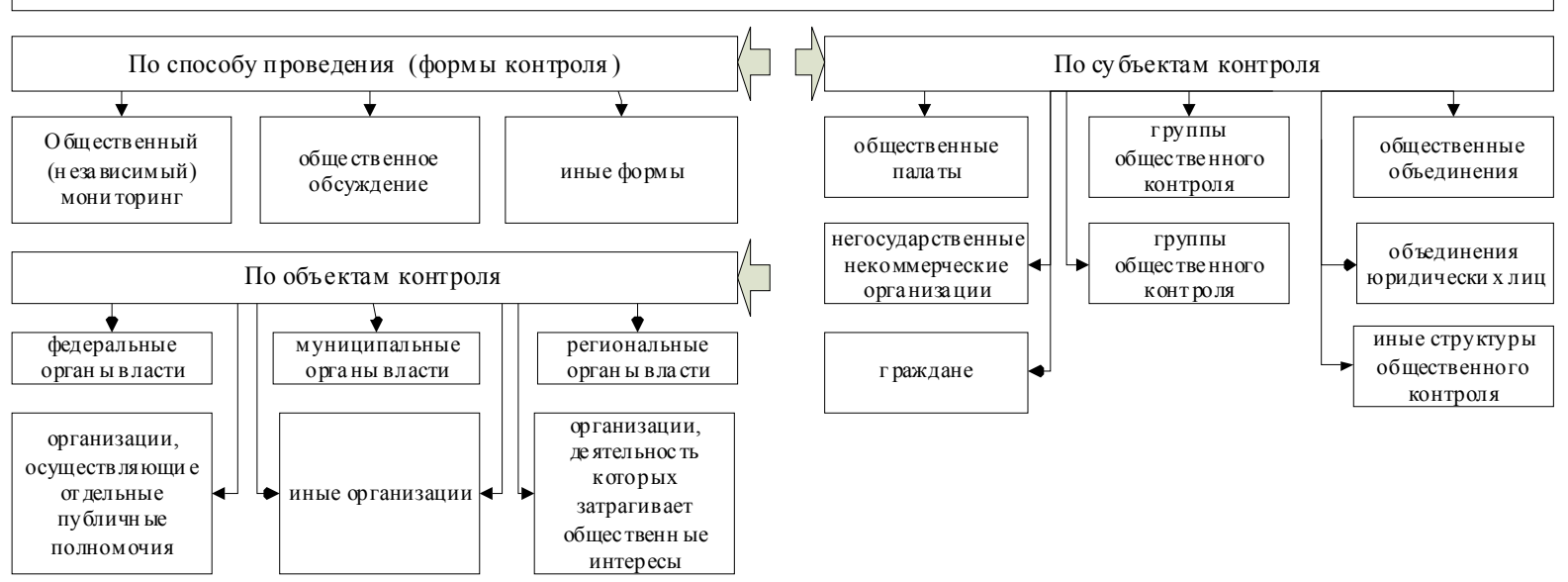

Рис. 2. Специальные виды общественного контроля 
7. Крицкая, М. С. Общественный контроль административной деятельности полиции (правовые и организационные аспекты) : дис. ... канд. юрид. наук : 12.00.14 / Крицкая Маргарита Сергеевна. М., 2017. $-206 \mathrm{c}$.

8. Старчикова, В. В. Общественный контроль в правовом государстве (теоретико-правовое исследование) : дис. ... канд. юрид. наук : 12.00.01 / Старчикова Валерия Викторовна. - М., 2014. - 190 с.

9. Трудовой кодекс Российской Федерации от 30.12.2001 № 197-Ф3 // Парламентская газета. 2002. -5 янв. (№ 2-5).

10. Федеральный закон «О некоммерческих организациях» от 12.01.1996 № 7-Ф3 // Собрание законодательства РФ. - 1996. - № 3. - Ст. 145.

11. Федеральный закон «Об Общественной палате Российской Федерации» от 04.04.2005 № 32-Ф3 // Парламентская газета. - 2005. - 9 апр. (№ 63-66).

12. Федеральный закон «Об основах общественного контроля в Российской Федерации» от 21.07.2014 № 212-Ф3 // Российская газета. - 2014. 23 июля (№ 163).

13. Федеральный закон от 05.04.2013 № 44-Ф3 «О контрактной системе в сфере закупок товаров, работ, услуг для обеспечения государственных и муниципальных нужд» // Российская газета. 2013. - 12 апр. (№ 80).

14. Философский словарь. - Электрон. текстовые дан. - Режим доступа: http://www.onlinedics.ru/ slovar/fil/n/nabljudenie.html. - Загл. с экрана.

15. Храмцов, А. Ф. Бюрократия и социальное государство / А. Ф. Храмцов. - М. : ИС РАН, 2010.$242 \mathrm{c}$.

\section{REFERENCES}

1. Avdeeva A.I. Pravovoe regulirovanie obshchestvennogo kontrolya za deyatelnostyu organov gosudarstvennoy vlasti subyektov Rossiyskoy Federatsii: dis. ... kand. yurid. nauk: 12.00.02 [Legal Regulation of Public Control Over the Activities of State Authorities of the Subjects of the Russian Federation. Cand. jurid. sci. diss]. Moscow, 2017. 241 p.

2. Bolshoy entsiklopedicheskiy slovar [Great Philosophical Dictionary]. URL: http://znachenieslova.ru/ slovar/encyclopedic/nablyudenie.

3. Goncharov V.V. Konstitutsionno-pravovye osnovy obshchestvennogo kontrolya $v$ Rossiyskoy Federatsii: monografiya [Constitutional and Legal Bases of Public Control in the Russian Federation. Monograph]. Moscow, Alicegroup Publ., 2019. 256 p.

4. Zabralova O.S. Obshchestvennyy kontrol $v$ Rossiyskoy Federatsii: monografiya [Public Control in the Russian Federation. Monograph]. Moscow, Navigator Publ., 2011. 122 p.
5. Zubarev S.M. O federalnom zakone «Ob osnovakh obshchestvennogo kontrolya» [On the Federal Law "On the Basics of Public Control"]. Problemy nauki administrativnogo prava: materialy konferentsii «Lazarevskie chteniya» (20-21 noyabrya 2014 g.). Moscow, Kontakt Publ., 2015, pp. 143-150.

6. Kilesso M.A. Printsipy obshchestvennogo kontrolya nad deyatelnostyu organov mestnogo samoupravleniya v Rossii [Principles of Public Control Over the Activities of Local Self-Government Bodies in Russia]. Probely v rossiyskom zakonodatelstve, 2016, no. 2, pp. 24-30.

7. Krickaya M.S. Obshchestvennyy kontrol administrativnoy deyatelnosti politsii (pravovye $i$ organizatsionnye aspekty): dis. ... kand. yurid. nauk: 12.00.14 [Public Control of Police Administrative Activities (Legal and Organizational Aspects). Cand. jurid. sci. diss.]. Moscow, 2017. 206 p.

8. Starchikova V.V. Obshchestvennyy kontrolv pravovom gosudarstve (teoretiko-pravovoe issledovanie): dis. ... kand. yurid. nauk: 12.00.01 [Public Control in a Legal State (Theoretical and Legal Research). Cand. jurid. sci. diss.]. Moscow, 2014. 190 p.

9. Trudovoy kodeks Rossiyskoy Federatsii ot 30.12.2001 № 197-FZ [The Labour Code of the Russian Federation of 30 December 2001 no. 197-FZ]. Parlamentskaya gazeta, 2002, 5 Jan., no. 2-5.

10. Federalnyy zakon «O nekommercheskikh organizatsiyakh» ot 12.01.1996 № 7-FZ [Federal Law “On Noncommercial Organizations" of 12 January 1996 no. 7-FZ]. Sobranie zakonodatelstva RF [Collection of Legislation of the Russian Federation], 1996, no. 3, art. 145 .

11. Federalnyy zakon «Ob Obshchestvennoy palate Rossiyskoy Federatsii» ot 04.04.2005 № 32-FZ [Federal Law "On the Public Chamber of the Russian Federation" of 4 April 2005 no. 32-FZ]. Parlamentskaya gazeta, 2005, 09 Apr., no. 63-66.

12. Federalnyy zakon «Ob osnovakh obshchestvennogo kontrolya v Rossiyskoy Federatsii» ot 21.07.2014 № 212-FZ [Federal Law “On the Basis of Public Control in the Russian Federation" of 21 July 2014 no. 212-FZ]. Rossiyskaya gazeta, 2014, July23, no. 163.

13. Federalnyy zakon ot 05.04.2013 № 44-FZ «O kontraktnoy sisteme v sfere zakupok tovarov, rabot, uslug dlya obespecheniya gosudarstvennykh i munitsipalnykh nuzhd» [Federal Law “About the Contract System in the Sphere of Procurement of Goods, Works, Services for State and Municipal Needs» of 5 April 2013 no. 44-FZ]. Rossiykaya gazeta, 2013, 12 Apr. (no. 80).

14. Filosofskiy slovar [Philosophical Dictionary]. URL: http://www.onlinedics.ru/slovar/fil/n/nab ljudenie.html.

15. Hramcov A.F. Byurokratiya i sotsialnoe gosudarstvo [Bureaucracy and the Welfare State]. Moscow, IS RAN, 2010. 242 p. 


\section{ВОПРОСЫ ЧАСТНОПРАВОВОГО РЕГУЛИРОВАНИЯ}

\section{Information About the Authors}

Roman Yu. Burimov, Candidate of Sciences (Jurisprudence), Associate Professor, Criminal Law Department, Astrakhan State University, Tatishcheva St, 20A, 414056 Astrakhan, Russian Federation, burimov-maksim@mail.ru, https://orcid.org/0000-0002-2169-9573

Oleg A. Ibragimov, Senior Engineer, The Academy of Management of the Ministry of Internal Affairs of Russia, Z i A. Kosmodemyanskikh St, 8, 125993 Moscow, Russian Federation, 464941@rambler.ru, https://orcid.org/0000-0002-7537-0685

\section{Информация об авторах}

Роман Юрьевич Буримов, кандидат юридических наук, доцент кафедры уголовного права, Астраханский государственный университет, ул. Татищева, 20A, 414056 г. Астрахань, Российская Федерация, burimov-maksim@mail.ru, https://orcid.org/0000-0002-2169-9573

Олег Александрович Ибрагимов, старший инженер, Академия управления МВД России, ул. 3. и А. Космодемьянских, 8, 125993 г. Москва, Российская Федерация, 464941@rambler.ru, https://orcid.org/0000-0002-7537-0685 